\title{
Silver Nanoparticles Modification of Ultra High Molecular Weight Polyethylene in Non-Aqueous Medium
}

\author{
V.N. GLUSHKO ${ }^{*}$, L.I. BLOKHINA ${ }^{1}$, E.E. ANISIMOVA ${ }^{1}$, \\ M.V. BOGDANOVSKAYA ${ }^{1}$, V.I. KOZHUKHOV ${ }^{1}$ and T.A. CHERDYNTSEVA ${ }^{2}$ \\ ${ }^{1}$ Federal State Unitary Enterprise «State Scientific Research Institute of Chemical \\ Reagents and High Purity Chemical Substances» (FSUE «IREA»), Bogorodskiy val, 3, \\ 107076, Moscow, 107076, Russian Federation. \\ 2Department of Microbiology, Faculty of Biology, M.V. Lomonosov Moscow State University, \\ Leninskie Gory, 1-12, 119991, Moscow, Russian Federation. \\ ${ }^{*}$ Corresponding author E-mail: tetrazoli@yandex.ru
}

http://dx.doi.org/10.13005/ojc/320630

(Received: November 07, 2016; Accepted: December 09, 2016)

\begin{abstract}
A series of experiments for obtaining modified with silver nanoparticles ultra-high molecular weight polyethylene (UHMWPE) is done. Optimal precursors are silver trifluoroacetate, silver nitrate and silver methanesulfonate. Three variants of UHMWPE modification is studied: 1) the polyol synthesis, 2) polymer processing silver nanoparticle colloid and 3) reduction of silver salt solution in the UHMWPE polymer matrix. It is found that the last method is optimal. The specific surface of obtained nanoparticles is $7.1-7.6 \mathrm{~m}^{2} / \mathrm{g}$ and the size varies in the range of $60-110 \mathrm{~nm}$.

The antibacterial activity of the composite samples to $E$. Coli and $S$. Aureus is studied. Inhibition of bacterial growth occurs at the level $10^{4} \mathrm{cfu} / \mathrm{ml}$ and $10^{6} \mathrm{cfu} / \mathrm{ml}$ respectively.
\end{abstract}

Keywords: Silver nanoparticles, UHMWPE, Polyol synthesis, Reduction, Silver trifluoroacetate, Silver methanesulfonate, Silver laurate, Silver palmitate, Antibacterial activity.

\section{INTRODUCTION}

One of the objects of modern medicine is the creation and improvement of materials for joint implant production (coxas, knee joints, spinal bones, dentofacial joints) for improvement their tribological and antimicrobic properties. Nowadays due to a number of properties (low constant of friction, high wear resistance and high chemical resistance $)^{1}$ the ultra-high-molecular-weight polyethylene holds a leading position as a material for prosthetics. There is number of works in literature devoted to the modification of UHMWPE with the metal nanoparticles, where the great attention is paid to introduction the silver nanoparticles into the polymer because of their unique antibacterial properties to the modification gains and UHMWPE ${ }^{2}$. The modified materials with silver nanoparticles have been already 
successfully used for the filter production and they are allowed to harmless pathogens, contained in the water for creation the special fabrics, paints and varnishes, which have antiseptic properties ${ }^{3}$. At the moment, there is a number of works where the polymers modified with the silver nanoparticles are used to create a new generation of implants and prostheses ${ }^{4}$.

The improvement of the earlier known methods and the development of such methods of nanomaterials producing identified main requirements that they must correspond:

- To provide the obtain of controlled composition materials with reproducible properties;

- To provide the temporal stability of nanomaterials, primarily provide the surface protection against spontaneous oxidation and sintering in the manufacturing process;

- To have high production and economical efficiency;

- $\quad$ To provide the obtain of nanomaterials with a specific particle size or the obtain of grains which size distribution must be sufficiently narrow, if necessary.

In this work we proposed a method of modified UHMWPE with the silver nanoparticles, which corresponds these requirements. The number of silver salts of organic acids and silver nitrate is used as precursors.

\section{Theoretical analysis}

Up to date the developed methods of nanocomposites obtaining are very diverse. The most common among the chemical and physical methods are listed below.

1) Inorganic nanoparticles and polymer are synthesized separately and then the nanoparticles are dispersed in the polymer (in its solution or melt). These methods include the dispersion in polymers of coarse particles with the colloid mills, ultrasound, high-frequency or arc crushing ${ }^{5}$.

2) Inorganic particles and polymer are synthesized separately, and after that the polymer is grafted to the inorganic core. An example of such synthesis is the nanoparticles microencapsulation by various polymers when applied surfactant on the particle, and then polymer grafts to the surfactant molecule ${ }^{6}$.

3) Inorganic nanoparticles which are obtained preliminary, serve as centers of heterophase polymerization of organic monomer ${ }^{7}$.

4) Inorganic nanoparticles are synthesized in situ in the polymer solution. By this strategy various chemicals belong, including photochemical and thermal methods of nanoparticles synthesis in polymers (recovery precursors, the decomposition of metal carbonyls in polymer matrices, etc. $)^{8}$.

5) Synthesis of inorganic nanostructures is combined with the polymerization of the organic monomer (creation of organicinorganic copolymers based on organometallic compounds that are compatible with organic monomers) ${ }^{9}$.

One of the main tasks in the developing polymer nanocomposites sphere is studying the nanoparticles formation processes in situ in a polymer matrix. There are various methods for nanoparticles forming in a polymer matrix, such as chemical synthesis methods in an organic solvent ${ }^{10}$, vacuum precipitating on the viscous polymeric materials ${ }^{11}$, with a plasma polymerization with the metal spatter ${ }^{12}$.

An important obtain aspect of the composite polymeric materials modified with nanoparticles, is the choice of introducing nanoparticles technology into the polymer structure. This also applies to the obtain of polymeric materials modified with silver nanoparticles. However, it is known that due to the strong hydrophobicity of UHMWPE the introduction of silver in its polymer matrix is complicated. Therefore, the preferred method of introducing silver to UHMWPE is dispersion in organic solvents.

To starting precursors for the impregnation of the polyethylene must correspond the certain requirements. First, they must have a solubility which is necessary to produce the desired concentration in the chosen solvent type, and a sufficiently high chemical stability under the chosen conditions.

As the precursors they selected: halogenated acetic acid salt (silver trifluoroacetate), sulfonic acid 
(silver methanesulfonate) salts of fatty acids (laurate, palmitate, and silver), and also the most used for this purpose - the silver nitrate.

For the silver nanoparticles modification of UHMWPE there were selected following methods from the literature:

1) Polymer impregnating with colloidal solution of silver nanoparticles ${ }^{13}$;

2) Synthesis of silver nanoparticles in the polymer matrix:

a) with agent presence ${ }^{13}$;

b) polyol synthesis ${ }^{14-17}$.

An ascorbic acid was selected as the reducing agent, and its effectiveness has been confirmed in previous works ${ }^{18,19}$.

\section{Experimental part}

\section{Reagents and solvents}

They used powdered UHMWPE of Ticona company (GUR-4120) with the molecular mass of 5.0 million $\mathrm{g} / \mathrm{mol}$.; silver nitrate - $99.9 \%$, trifluoroacetic acid - 99\%, methanesulfonic acid - 99\%, lauric acid - 99\%, palmitic acid - 99\%, ethylene glycol - 99\%, ethanol - 95\%, methanol - 99\%, ascorbic acid - $99 \%$, silver carbonate - $99 \%$ in these experiments.

\section{Obtain of silver salts}

Silver trifluoroacetate $\mathrm{CF}_{3}$ COOAg (1a)

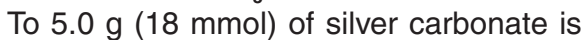
added $60 \mathrm{ml}$ of trifluoroacetic acid and is stirred for 30 minutes. The reaction mixture is boiled down to dryness and is received $7.0 \mathrm{~g}(72 \%)$ of a white crystalline solid. Calculated: C - 10,874. Found C - 10,861.

Table 1: Atomic emission spectroscopy and SEM data in the modification of UHMWPE with silver nanoparticles by polyol

\begin{tabular}{llll}
\hline Method & $\begin{array}{l}\text { Silver } \\
\text { salt }\end{array}$ & $\begin{array}{l}\text { Silver } \\
\text { content, } \%\end{array}$ & Size distribution of nanoparticles of dispersion \\
\hline 1.1 & $1 \mathrm{a}$ & 0.05 & A significant amount of silver nanoparticles with \\
1.2 & & 0.07 & the size of $60-110 \mathrm{~nm}$ was found. \\
1.1 & 1c & 0.04 & There is an aggregation of silver. \\
1.2 & & 0.07 & \\
\hline
\end{tabular}

Table 2: Atomic emission spectroscopy and SEM data in the modification of UHMWPE with impregnation with colloidal solution of silver nanoparticles

\begin{tabular}{ccccc}
\hline Method & $\begin{array}{c}\text { Silver } \\
\text { salt }\end{array}$ & Solvent 2 & $\begin{array}{c}\text { Silver } \\
\text { content, \% }\end{array}$ & $\begin{array}{c}\text { Nanoparticles } \\
\text { size, } \mathbf{~ n m ~}\end{array}$ \\
\hline 2.1 & $1 \mathrm{a}$ & ethylene glycol & 0.22 & $65-100$ \\
2.2 & & & 0.35 & $60-100$ \\
2.1 & 1b & & 0.11 & $65-90$ \\
2.2 & & & 0.30 & $70-95$ \\
2.1 & 1c & & 0.19 & $70-110$ \\
2.2 & 1d & methanol & 0.33 & $70-110$ \\
2.1 & & ethanol & 0.14 & $65-100$ \\
& 1e & methanol & 0.12 & $70-110$ \\
& & ethanol & 0.04 & $70-100$ \\
& & & 0.03 & $65-95$ \\
\hline
\end{tabular}




\section{Silver methanesulphonate $\mathrm{CH}_{3} \mathrm{SO}_{3} \mathrm{Ag}$ (1b)}

$5.0 \mathrm{~g}(18 \mathrm{mmol})$ of silver carbonate is dissolved in $30 \mathrm{ml}$ of methanesulfonic acid. To this solution is added $50 \mathrm{ml}$ of isopropanol, after which there is the precipitate. The reaction mixture is cooled to $0^{\circ} \mathrm{C}$ and the precipitate is filtered off, after which it is washed with $10 \mathrm{ml}$ of isopropanol and winded. Obtained $5.91 \mathrm{~g}(80 \%)$ of silver methanesulfonate. Calculated: C - 5,917, H - 1.499; S - 15.798. Found: C - 5,978; H - 1.517; S - 15.826 .

\section{Silver laurate $\mathrm{C}_{11} \mathrm{H}_{23} \mathrm{COOAg}$ (1c)}

To $5.0 \mathrm{~g}(22.4 \mathrm{mmol})$ of the sodium salt solution of lauric acid in $300 \mathrm{ml}$ of distilled water is added dropwise a solution of $3.8 \mathrm{~g}(22.4 \mathrm{mmol})$ of silver nitrate in $170 \mathrm{ml}$ of distilled water. The reaction is stirred for two hours, white precipitate. The precipitate is filtered off, washed with $100 \mathrm{ml}$ of water and dried in a desiccator. Obtained $4.14 \mathrm{~g}$ (60\%) silver laurate. Calculated: C - 46,925; H - 7,548. Found: C - 46,931; N - 7.530.

\section{Silver palmitate $\mathrm{C}_{15} \mathrm{H}_{31}$ COOAg (1e)}

To $5.0 \mathrm{~g}(13.8 \mathrm{mmol})$ of the sodium salt suspension of palmitic acid in $300 \mathrm{ml}$ of distilled water is added dropwise a solution of $2.34 \mathrm{~g}$ $(13.8 \mathrm{mmol})$ silver nitrate in $170 \mathrm{ml}$ of distilled water. The reaction is stirred for two hours, white precipitate. The precipitate is filtered off, washed with $100 \mathrm{ml}$ of water and dried in a desiccator. Obtained $5.8 \mathrm{~g}(89 \%)$ of silver palmitate. Calculated: $\mathrm{C}-52,850 ; \mathrm{H}-8,531$. Found C - 52,939; H - 8,510.

The received silver salt was used to modify UHMWPE

\section{The polyol synthesis}

Method 1.1

To $10 \mathrm{ml}$ of ethylene glycol was added $0.5 \mathrm{~g}$ of UHMWPE, then it was heated to $115^{\circ} \mathrm{C}$ and stirred for one hour. After that was poured 20 micromole of the solution silver salt of $1 a, c$ in 10 $\mathrm{mL}$ of ethylene glycol and kept at this temperature for 1 hour. UHMWPE is filtered off, washed with 250 $\mathrm{ml}$ of distilled water and dried at $110^{\circ} \mathrm{C}$.

Table 3: Atomic emission spectroscopy and SEM data in the formation of silver nanoparticles in a polymer matrix UHMWPE

\begin{tabular}{ccccc}
\hline Method & Silver salt & Solvent2 & $\begin{array}{c}\text { Silver } \\
\text { content, } \%\end{array}$ & $\begin{array}{c}\text { Nanoparticles } \\
\text { size, } \mathbf{n m}\end{array}$ \\
\hline 3.1 & 1a & ethylene glycol & 0.27 & $65-100$ \\
3.2 & & & 0.44 & $60-100$ \\
3.1 & 1b & & 0.15 & $65-90$ \\
3.2 & \multirow{2}{*}{ 1c } & & 0.35 & $70-95$ \\
3.1 & \multirow{2}{*}{ 1d } & methanol & 0.24 & $70-110$ \\
3.2 & \multirow{2}{*}{ 1e } & ethanol & 0.37 & $70-110$ \\
3.1 & & methanol & 0.26 & $65-100$ \\
& & ethanol & 0.07 & $70-110$ \\
& & 0.06 & $65-100$ \\
& & &
\end{tabular}

Table 4: The effect of UHMWPE powder on the antibacterial activity

\begin{tabular}{lccccccc}
\hline Samples & \multicolumn{3}{c}{ S. aureus, CFU/mI } & \multicolumn{3}{c}{ E. coli, CFU/ml } \\
& $10^{2}$ & $10^{4}$ & $10^{6}$ & $10^{7}$ & $10^{4}$ & $10^{6}$ & $10^{7}$ \\
\hline Silver methanesulfonate & - & \pm & + & + & - & \pm & \pm \\
Silver trifluoroacetate & - & \pm & + & + & - & \pm & \pm \\
control & + & + & + & + & - & + & + \\
\hline
\end{tabular}




\section{Method 1.2}

To a solution of 20 micromole of silver salt $1 \mathrm{a}, \mathrm{c}$ in $10 \mathrm{~mL}$ of ethylene glycol was added $0.5 \mathrm{~g}$ of UHMWPE and heated to $115^{\circ} \mathrm{C}$ and sonicated with frequency $20000 \mathrm{~Hz}$ for 30 minutes. UHMWPE was filtered off, washed with $250 \mathrm{ml}$ of distilled water and dried at $110^{\circ} \mathrm{C}$.

Processing of polymer with colloid silver nanoparticles

Method 2.1

To a solution of 20 micromole of silver salt 1a-e in $20 \mathrm{ml}$ of solvent $2\left(\mathrm{C}=10^{-3} \mathrm{M}\right)$ solution with stirring, was poured $1.76 \mathrm{mg}$ (10 micromole) of ascorbic acid in 10 milliliters of solvent $3(\mathrm{C}=$ $10^{-3} \mathrm{M}$ ). Then was added $0.5 \mathrm{~g}$ of UHMWPE which is pre-impregnated with ethanol and is stirred for 2 hours. The suspension is filtered on a Shott filter, washed the precipitate with $500 \mathrm{ml}$ of distilled water and dried at $110^{\circ} \mathrm{C}$.
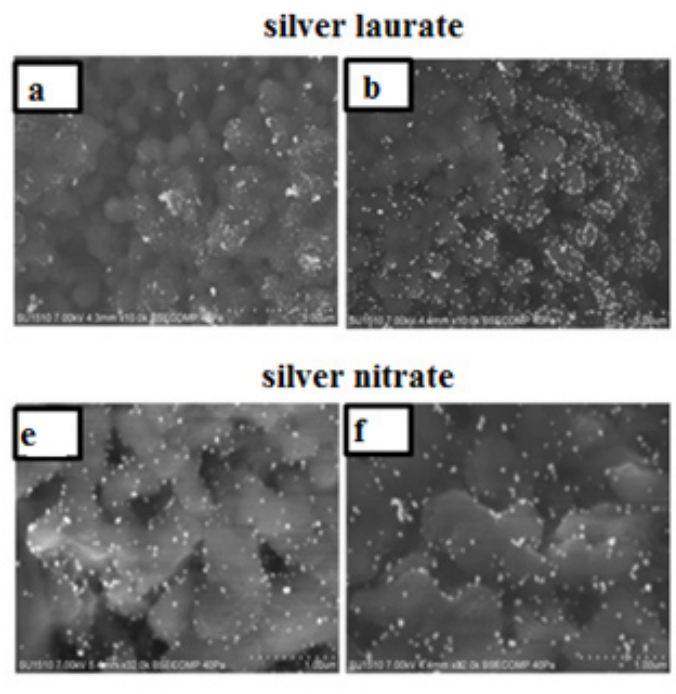

ilver nitrate
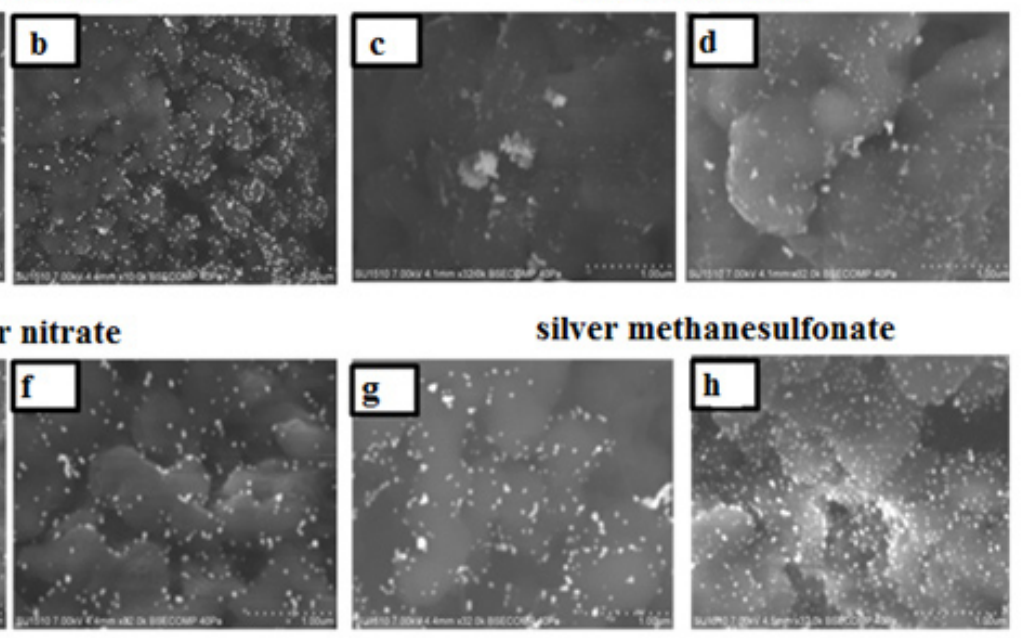

silver methanesulfonate
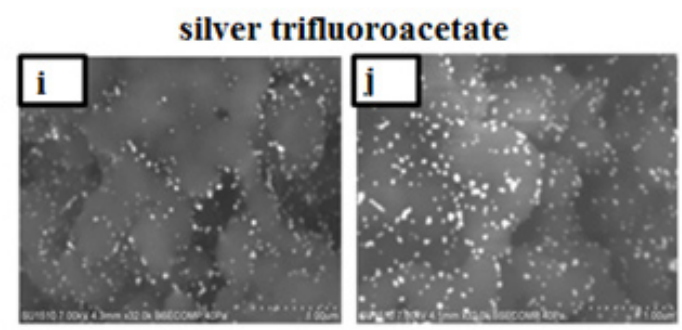

\section{Method 2.2}

To a solution of 40 micromoles of silver salt 1a-e in $20 \mathrm{ml}$ of solvent $2\left(\mathrm{C}=2 \cdot 10^{-3} \mathrm{M}\right)$ was poured with stirring the solution $3.52 \mathrm{mg}(2 \bullet 10$ micromoles) of ascorbic acid in 10 milliliters of solvent $3\left(C=10^{-3}\right.$ $\mathrm{M})$. Then was added $0.5 \mathrm{~g}$ of UHMWPE, which is preimpregnated with ethanol and stirred for 2 hours. The suspension is filtered on a Shott filter, the precipitate is washed with $500 \mathrm{ml}$ of distilled water and dried at $110^{\circ} \mathrm{C}$.

Recovery of silver salt solution in the polymer matrix UHMWPE

Method 3.1

To a solution of 20 micromole 1a-e of silver salt in $20 \mathrm{ml}$ of solvent $2\left(\mathrm{C}=10^{-3} \mathrm{M}\right)$ was added $0.5 \mathrm{~g}$ of UHMWPE, which is pre-impregnated with ethanol. To the resulting suspension under stirring solution is poured $1.76 \mathrm{mg}$ (10 micromole) of ascorbic acid in 10 milliliters of solvent $3\left(C=10^{-3} \mathrm{M}\right)$ and stirred for 
2 hours. The suspension was filtered on a sintered glass filter, the precipitate was washed with $500 \mathrm{ml}$ of distilled water and they dried at $110^{\circ} \mathrm{C}$.

\section{Method 3.2}

To a solution of 40 micromoles $1 \mathrm{a}-\mathrm{e}$ the silver salt in $20 \mathrm{ml}$ of solvent $2\left(\mathrm{C}=2 \cdot 10^{-3} \mathrm{M}\right)$ was added $0.5 \mathrm{~g}$ of UHMWPE, which is pre-impregnated with ethanol. To the resulting suspension was poured under stirring solution $3.52 \mathrm{mg}$ (10 micromole) of ascorbic acid in 10 milliliters of solvent $3(\mathrm{C}=2$ • $10^{-3} \mathrm{M}$ ) and stirred for 2 hours. The suspension was filtered on a Shott filter, the precipitate was washed with $500 \mathrm{ml}$ of distilled water and dried at $110^{\circ} \mathrm{C}$.

\section{Antimicrobial activity}

Antimicrobial activity of the samples was determined towards to gram-positive bacteria Staphylococcus aureus and to gram-negative bacteria Escherichia coli. Test organism E. coli was cultured on meat-peptone broth, and $S$. aureus on meat-peptone broth with $6 \% \mathrm{NaCl}$. To assess the antibacterial activity of microbial of UHMWPE powder they seed the microorganisms cultures in the meatpeptone at a concentration from $10^{2}$ to $10^{7} \mathrm{CFU} / \mathrm{ml}$, after that they add the test samples of composite powders, which activity qualitatively was assessed by the presence or absence of meat-peptone broth turbidity due to bacteria propagation. The samples were incubated at $37^{\circ} \mathrm{C}$ during the day.

\section{RESULTS AND DISCUSSIONS}

There were considered three modification methods of UHMWPE with silver nanoparticles: 1) the polyol synthesis 2) Processing of polymer with colloid silver nanoparticles polymer processing silver nanoparticle colloid and 3) Recovery of silver salt solution in the polymer matrix UHMWPE.

\section{The polyol synthesis}

According to the first method the recovering of silver salt is getting with glycol aldehyde, which is forming under the influence of a high temperature from the glycol. According to the atomic-emission spectrometry with inductively coupled plasma the silver content of UHMWPE is not more than $0.07 \%$, according to scanning electron microscopy (SEM) there is a significant amount of aggregated silver in polymer (data shown in Table 1).

The second method is that the UHMWPE powder which is previously wetted with ethanol, is impregnated with stirring for 2 hours by the

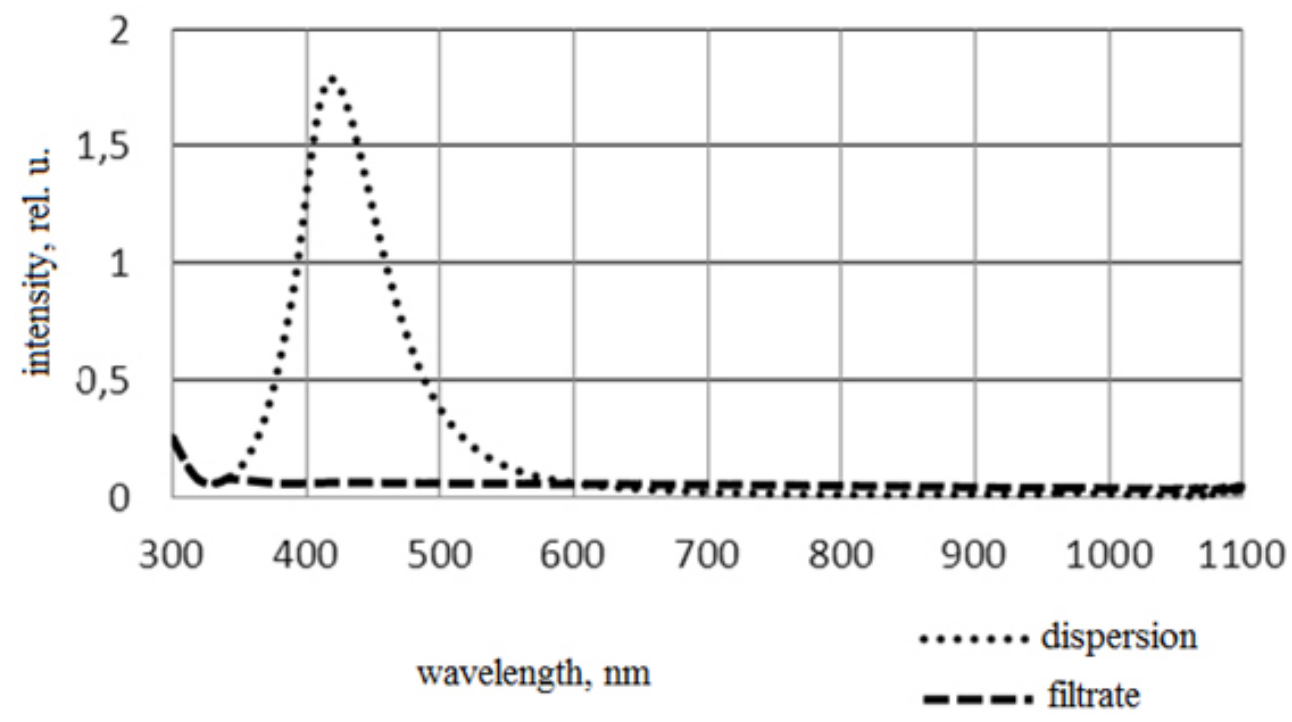

Fig. 2: The comparison of the absorption spectra of silver nanoparticle dispersion, which is obtained by recovery of silver methanesulfonate and filtrate after UHMWPE impregnation 
silver colloidal solution, which is obtained previously ${ }^{18,19}$. Then the powder is washed with distilled water and dried (see Table 2). Thus stable dispersion was obtained previously with the reduction of silver trifluoroacetate ${ }^{18}$ and silver methanesulphonate ${ }^{19}$.

According to the third method, to a solution of a silver salt in an organic solvent they add UHMWPE powder, which is impregnated with ethanol previously, and then they add a reducing agent (table 3). It should be noted that pre-impregnation of ultra-high molecular polymer powder with ethanol ensures quick absorption of solution in volume of the polymer matrix.

Figure 1 shows the received with the SEM method, the image of UHMWPE powder, which is modified with silver nanoparticles. With using trifluoroacetate, methanesulfonate, laurate, silver nitrate there was found a significant amount of silver nanoparticles with the size of $60-110 \mathrm{~nm}$ equally spaced in the UHMWPE matrix. In the samples obtained by treating of UHMWPE powder with a dispersion of nanosilver is observed nonequilibrium distribution of silver nanoparticles by using the fatty acid there is the presence of aggregating. With recovering silver palmitate in both cases there is an aggregation of silver, the colloidal solution is poor, and therefore there is only a small amount of nanoparticles on the UHMWPE matrix.

The content of silver nanoparticles in the polymer ranges by using different salts, salt concentration, the reducing agent and the reaction conditions. According to the atomic-emission spectrometry with inductively coupled plasma, the best results is observed when they use as precursors the silver trifluoroacetate - in this case, the content of silver in the polymer is $0.22-0.44 \%$; silver nitrate $0.19-0.37 \%$, silver methanesulfonate $0.11-0.35 \%$. In view of the low solubility of silver salts of fatty acids it is impossible to increase the salt concentration in the organic solvent. Thus, when using silver laurate, silver content can not exceed $0.26 \%$, silver palmitate $-0.07 \%$.

The specific surface of nanoparticles according to the data obtained by the analyzer nanoparticle surface area is 7.1-7.6 $\mathrm{m}^{2} / \mathrm{g}$.

To monitor the transfer completeness of passage nanosilver from the solution into the UHMWPE matrix there had been taken spectra of

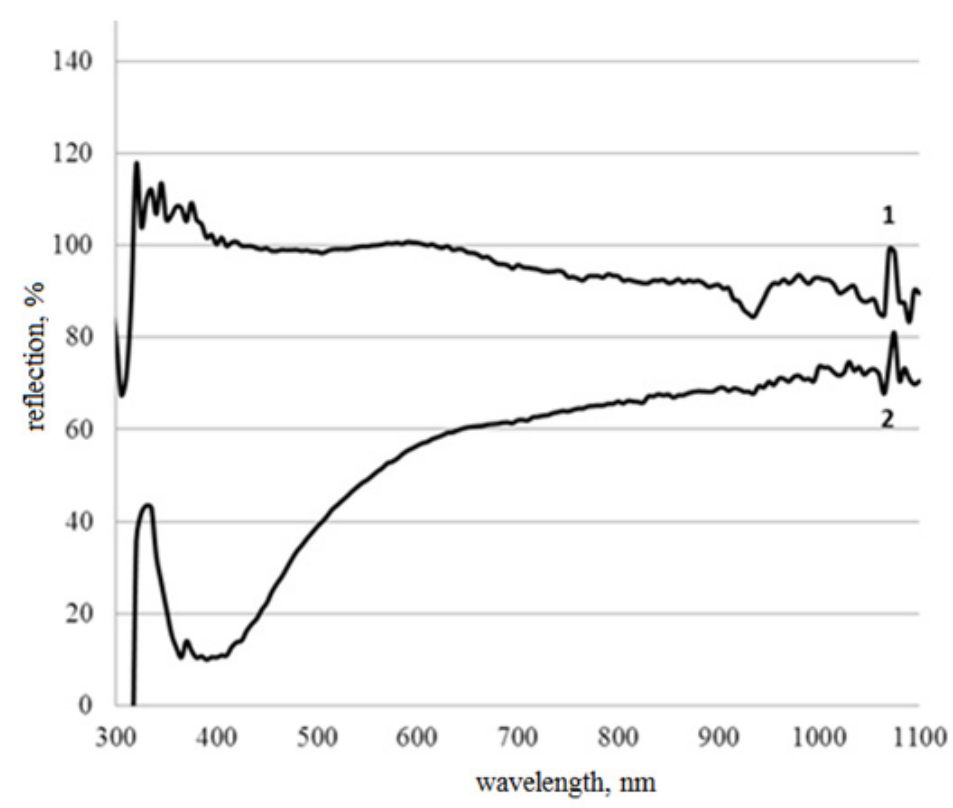

Fig. 3: Diffuse reflection spectrum of the UHMWPE (1) and spectrum of the UHMWPE modified by silver nanoparticles (2) 
the filtrate absorption. Figure 2 shows that on the absorption spectrum of the filtrate there is no peak at a wavelength of $400-420 \mathrm{~nm}$, which corresponds to the peak of the plasmon resonance of silver nanoparticles, it indicates about complete or almost complete absence of silver nanoparticles in the filtrate and their sorption on the polymer matrix.

Also, using an integrating sphere there were read spectra of the reflectance diffuse UHMWPE powders, modified with the silver nanoparticles (Fig. 3). When there is a comparison with the spectrum of the original powder UHMWPE there is minimum at a wavelength of $400 \mathrm{~nm}$, which allows to judge about the presence of silver nanoparticles. Also it should be noted that this minimum corresponds to the peak of the plasmon resonance of silver nanoparticles in dispersion (Fig. 2).

Samples, which were obtained by reduction of silver trifluoroacetate and methanesulfonate were investigated for bactericidal activity. The results are shown in the Table 4.

Table 4 shows that UHMWPE powder containing silver nanoparticles in a varying degree have a antimicrobial activity. The full growth inhibition of $S$. aureus with the samples obtained by reduction of silver trifluoroacetate and methanesulfonate is at an initial concentration of $10^{2} \mathrm{CFU} / \mathrm{ml}$ but at the initial concentration of $104 \mathrm{CFU} / \mathrm{ml}$ there is a partial suppression of bacterial growth.

The growth of $E$. coli in the control is observed at an initial concentration of $10^{6} \mathrm{CFU} / \mathrm{ml}$. At the initial concentration the both samples completely inhibit bacterial growth, and at a concentration of $10^{7}$ $\mathrm{CFU} / \mathrm{ml}$ - in part.

\section{CONCLUSION}

There were considered approaches to modification of ultrahigh molecular weight polyethylene with silver nanoparticles. It was found, that for the best way of modification of UHMWPE with silver nanoparticles, the most suitable are precursors such as trifluoroacetate, methanesulfonate, nitrate and silver, and the recovery of silver salt solution should be carried out in the matrix of UHMWPE. The obtained samples have antibacterial activity towards to E. Coli and S. Aureus.

\section{ACKNOWLEDGMENTS}

The work was supported by the Russian Federation Ministry of Education and Science under the grant agreement 1 14.576.21.0024 of 27 June 2014 (the project ${ }^{1}$ RFMEFI57614X0024).

\section{REFERENCES}

1. Galibeev S.S.; Khayrullin R.Z.; Arhireev V.P. UHMW polyethylene. Trends and Prospects. J. Bulletin of Kazan Technological University. 2008, 2, 50-55.

2. Domenech B.; Munoz M.; Muraviev D.N.; Macanas J. Polymer-Silver Nanocomposites as Antibacterial materials. Formatex. 2013, 630-640.

3. Revina A.A.; Egorova E.M. Possibilities of application of nanotechnology in the production of paints and coatings. Chemical industry. 2001, 4. 28-32.

4. Patent RU 02437645 C1, 27.12.2011. Kalivradzhiyan E.S.; Kalinichenko V.S.; Kalinichenko N.V.; Kalinichenko T.P.; Lakiza V.V.; Podoprigora A.V.; Pozov D.T.; Removable plate dentures with silver in nanoform.
5. Litmanovich O.E. Patterns of interaction of macromolecules with the nanoparticles of metals and synthesis psevdomatrichny sols of metal-polymer nanocomposites. Macromolecular compounds. 2008, 7, 1370.

6. Bedanokov A.Y.; Borisov V.A.; Mikitaev A.K. The properties of polymer nanocomposites. Plastics. 2007, 5, 26.

7. Sokolov V.I. Chiral stereochemistry nanoparticles. Coordination chemistry. 2009, 8,563-575.

8. Nyquist N.E.; Lysenko E.L.; Serimaa R.; Pirkkalainen K.; Vainio U.; Lavrent'ev V.K.; Medvedev D.A.; Shahmin A.L.; Saprykin N.N.; Novoselov N.P. Cellulose as a nanoreactor for nickel nanoparticles. Macromolecular compounds. 2008, 1, $63-70$. 
9. Vishnjakova E.A.; Zhukov S.V.; Markov S.M.; Likhatskaya M.N.; Mikhalin Y.L. Determination conditions for the formation of silver nanoparticles in the reduction of glucose in aqueous solutions. Journal of Siberian university. Chemistry. 2009, 2, 4855.

10. Kreibig U.; Vollmer M.; Optical Properties of Metal Clusters. The Springer Series in Materials Science. Berlin: Springer. 1995, 234.

11. Abdullin S.N.; Stepanov A.L.; Osin Yu.N.; Khaibullin I.B. Kinetics of silver nanoparticle formation in a viscous-flow polymer. Surf. Sci. 1998, 395, 242-245.

12. Quinten M.; Heilmann A.; Kiesow A. Refined interpretation of optical extinction spectra of nanoparticles in plasma polymer films. Appl. Phys. 1999, 4, 707-712.

13. Vishnyakov E.A.; Seljutin G.E.; Gavrilov Y.Y.; Saykova S.V.; Romanchenko A.S.; Mazurov E.V.; A.N.; Kokorin A.N.; Mikhlin Y.L. Preparation of composites based on ultrahigh molecular weight polyethylene having antibacterial properties. Journal of Siberian Federal University. Chemistry. 2013, 4, 372-379.
14. Wiley B.; Sun Y.; Mayers B.; Xia Y. Shapecontrolled synthesis of metal nanostructures: the case of silver. Chem. Eur. J.. 2005, 2, 454-463.

15. Sun Y., Xia Y. Large-Scale Synthesis of Uniform silver nanowires through a soft selfseeding. polyol process. Adv. Mater. 2002, 11, 833-837.

16. Chen C.; Wang L. Yu H.; Jiang G.; Yang Q.; Zhou J.; Xiang W.; Zhang J. Study on the growth mechanism of silver nanorods in the nanowire-seeding polyol process. Mater. Chem. Phys. 2008, 107, 13-17.

17. Silvert P.-Y., Herrera-Urbina R. Preparation of colloidal silver dispersions by the polyol process Part 1 -Synthesis and characterization. J. Mater. Chem. 1996, 4, 573-577.

18. Glushko V.N., Sadovskaya N.Y., Usova O.A., Blokhina L.I., Kozhukhov V.I. Features of Obtaining Silver Nanoparticles in Non-Aqueos Media by Reduction of Silver Trifluoroacetate. Orient J Chem. 2015, 4, 2515-2520.

19. Glushko V., Blokhina L., Sadovskaya N., Kozhukhov V. Nonaqueous preparation of stable silver nano particles dispersions from organic sulfonic acids. Orient J Chem. 2016, 2, 789-797. 